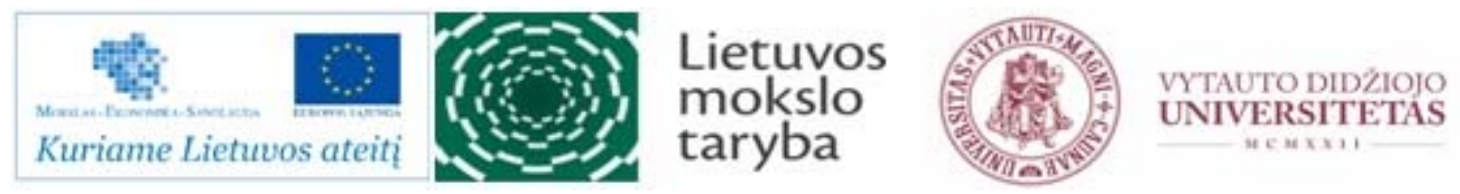

\title{
LEARNING TO LEARN COMPETENCE IN THE CONTEXT OF ADULT EDUCATION
}

\author{
Dalia Staniulevičienė \\ Vytauto Didžiojo universitetas
}

\begin{abstract}
The purpose of this article is to provide a description of learning to learn competence, highlighting the issue of abilities that are needed. The necessary abilities, as components of learning to learn competence, are characterized. In order to achieve the purpose, a theoretical frame is provided in this article. Also preliminary data of the quantitative pilot research presented. It is important to mention, that learning to learn is a process in which learning situations are reflectively analysed in an effort to understand oneself. Therefore, through learning to learn, the individual can identify his or her strengths and weaknesses, and thus use personally appropriate learning strategies. The model of learning to learn competence, constructed by the author of this article, is presented.
\end{abstract}

Keywords: ability, competence, learning to learn, reflection

\section{Introduction}

The concept of contemporary society as both a knowledge society and a learning society, is closely associated with the image of a world in which all learning is seen in a wider context. This includes the concept of life-long continuous learning, where individuals are able to manage knowledge, upgrade it and choose what is appropriate in a particular context; they must constantly learn and understand what they have learned so that they can adapt this in new and rapidly changing situations.

Equal opportunities, social cohesion and active citizenship are priorities that should be promoted not only in the European, but also in the global context. Education and training should enable all citizens to develop skills and learning to learn the competences that are important when seeking employment, and, while working, still continue to learn throughout their lives: this would encourage active citizenship and intercultural dialogue. Short-comings in education should be reduced by using high-quality means of involvement in the learning process (Education and Training 2020 (ET 2020)).

In this context, what is important is learning to learn, which refers to a person's ability to keep on learning, to organize his or her own learning process, including the effective management of time and information, both individually and in groups. As has been asserted, "learning to learn engages learners to build on prior learning and life experience to use and apply knowledge and skills in a variety of situations - at home, at work, in education and training." (Lifelong learning skills. European Reference Framework, 2007). However, the question 
remains about how to understand learning to learn competence in today's context. To answer this question in the present article, scholarly studies about learning to learn competence are analysed.

The object of this study is the structure of learning to learn competence, while its purpose is to provide a description of learning to learn competence, highlighting the issue of abilities that are needed.

The tasks are:

- to characterize the necessary abilities, as components of learning to learn competence;

- to present a model of learning to learn competence;

- to discuss the main reasons for gaining learning to learn competence.

In order to achieve the purpose, a theoretical frame is provided in this article. Also preliminary data of the quantitative pilot research presented.

\section{Learning to learn competence: the theoretical background}

Modern competences require that a learner not only have appropriate knowledge and skills, but also the necessary personal qualities and ability to work flexibly and appropriately both in familiar and unfamiliar situations. In life today, learning is understood in a broad sense so that traditional learning theories have to be viewed from a different angle. According to K. Iller (2003), the theory of learning is based on two fundamental assumptions. The first is that learning is a process consisting of interaction with the outside (external interaction) and the social, cultural and material base, as well as an internal psychological process, which plays an important role in current knowledge which is related to previous studies. The second assumption is that learning involves three dimensions: the cognitive dimension, which includes knowledge and skills, the emotional dimension, that of feelings and motivations, and the social dimension, communication and cooperation, which involve the social context. Learning to learn competence as a complex combination in LLL (lifelong learning) brings together knowledge, skills, values, attitudes and personal preferences which helping to learn all one's life in formal and informal ways.

Within the framework of European Commission recommendations, the following definition of the concept of learning to learn is given: learning to learn is the ability to persevere with learning, to organize one's learning, including effective management of time and information, both individually and in groups (Lifelong Learning. European Reference Framework, 2007).

When considering scholarly studies, we can draw the conclusion that, in analysing learning to learn, this holistic concept of values, attitudes, interests, and knowledge, skills and understanding includes understanding oneself and one's characteristics as an individual learner. In discussions about learning to learn, in this context specialists emphasize relationships with the learner's history and motivation. Learning to learn is important because it leads to a 
"purposeful learning" (Black et al., 2006) so that in discussing learning to learn the learner's self-awareness and responsibility should not be forgotten.

Therefore the definition of learning to learn competence includes competencerelated skills.

Learning to learn is a process in which learning situations are reflectively analysed in an effort to understand oneself. Therefore, through learning to learn, the individual can identify his or her strengths and weaknesses, and thus use personally appropriate learning strategies. This is significant for learners motivation, confidence and belief in what they are doing in conjunction with their previous experience. Learning to learn engages learners to build on prior learning and life experience to use and apply their knowledge and skills in a variety of situations - at home, at work, in education and training (Lifelong learning competence. European Reference Framework, 2007).

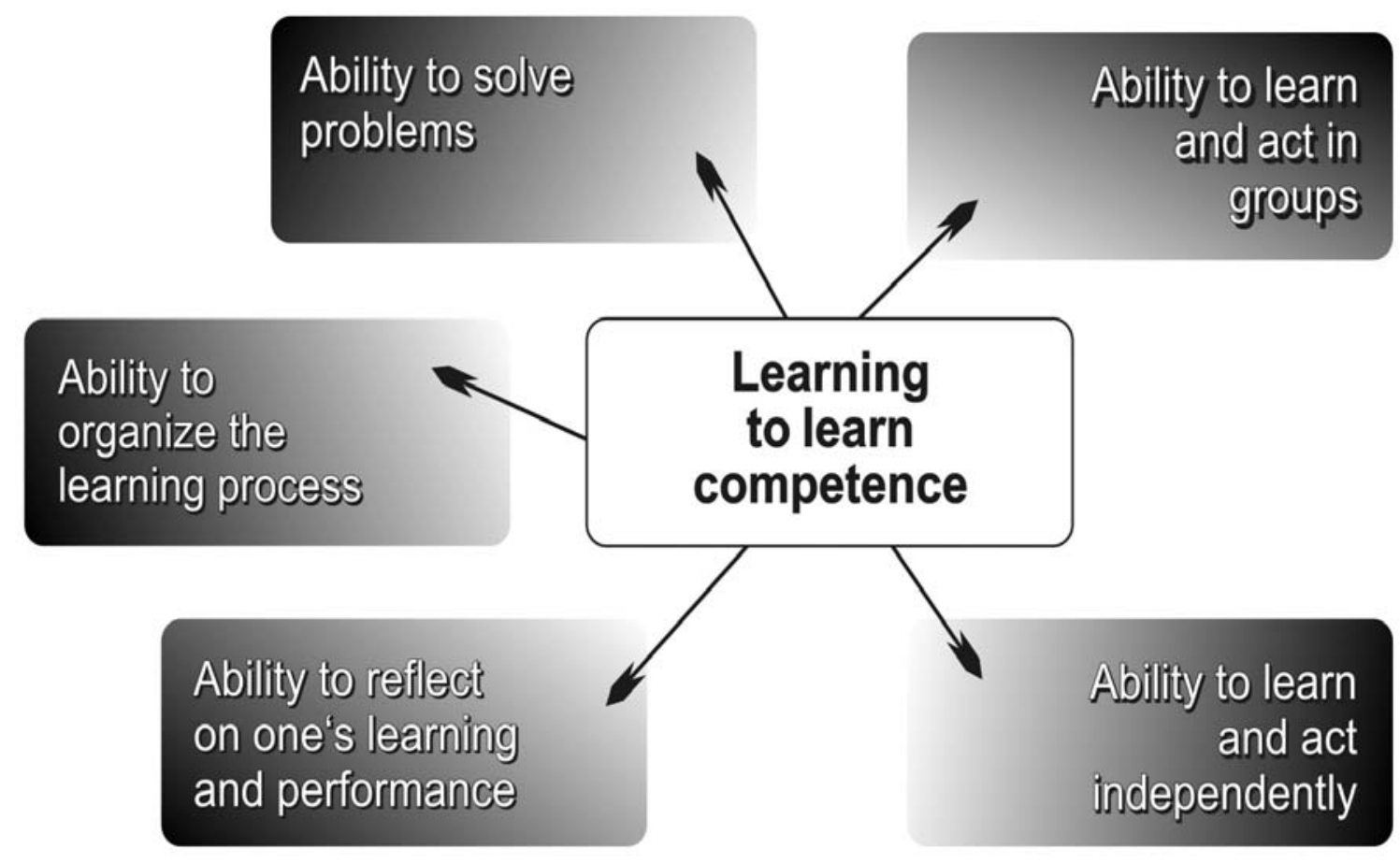

Figure 1 The abilities, constructing learning to learn competence

In discussing the importance of learning to learn, an understanding of the process of learning has to include issues like developing skills to overcome obstacles and solve problems in order to learn successfully. Problem-solving is a particularly significant element in the process of learning to learn. This specific competence involves gaining, processing and assimilating new knowledge and skills, along with looking for help and using it to resolve problems connected with learning.

"When learning is directed towards particular work or career goals, the learner has to be aware of the competences, knowledge, skills and qualifications that are 
necessary for these goals to be achieved. In all cases, in learning to learn, learners have to know and understand the learning strategies which they have adopted, their skills and qualifications, strengths and weaknesses and should be able to search for the educational and training opportunities, as well as the guidance and/or the support they can get. Thus, the ability to learn and to act independently is important in the process of learning (Bendrieji visa gyvenimą..., 2007).

According to the specialists analysing learning to learn, it is impossible to distinguish between the ability to learn and the learning process itself; the major focus is on the term "learning practice", including interpersonal processes. C. Bereiter and M. Scardamalia (1989) also argue that conscious learning, acquiring skills and learning to choose the right strategies to achieve the learning objectives, require practice, and demand that the learners take responsibility for their own learning; they should be able to do this in more than one way, both individually and in groups. In order to do this, students have to be motivated to learn, and have an understanding of themselves and others as learners and then adjust their learning process accordingly. Thus the ability to learn and act in a group is singled out in discussions of learning to learn competence as among the important skills.

J. Hautamäki and others (2002) also emphasize the importance of the learner's personality and self-regulation process. Thus, in this context, according to scholarship on learning to learn competence, these essential skills are distinguished: the ability to organize their own learning process, the ability to learn and function independently; the ability to learn and function within the group; the ability to solve problems, the ability to discuss (reflect on) their learning and activities (Figure1).

Looking at the model (Figure 2), problem-solving scenarios, it has been noted that their use enables learners to acquire learning skills which help implement knowledge in solving problems.

It is significant for learners to apply relevant knowledge to problem-solving, and during hands-on activity to check what they have learned. Learning takes place in a decentralized manner and does not attempt to go beyond the limits of the discipline. In the learning process openness towards others, reflection, and selfassessment are important. Similarly, what learners know is also connected to what the theory suggests.

During the process, the script changes, and comprehensive skills in the discipline are united. The learners can see themselves as professionals, linking disciplines and the learners' personal positions. The problem-based learning mode is a form of learning in which learners aim to impart knowledge through programs that offer multiple models of action, knowledge, causality, multiple (repeated) reflection along with opportunities for the learners to meet challenges, evaluate and question them. Learners explore the structures and 
systems both within disciplines and in their professional field (Savin-Baden, 2000, Teresevičienè et al., 2004).

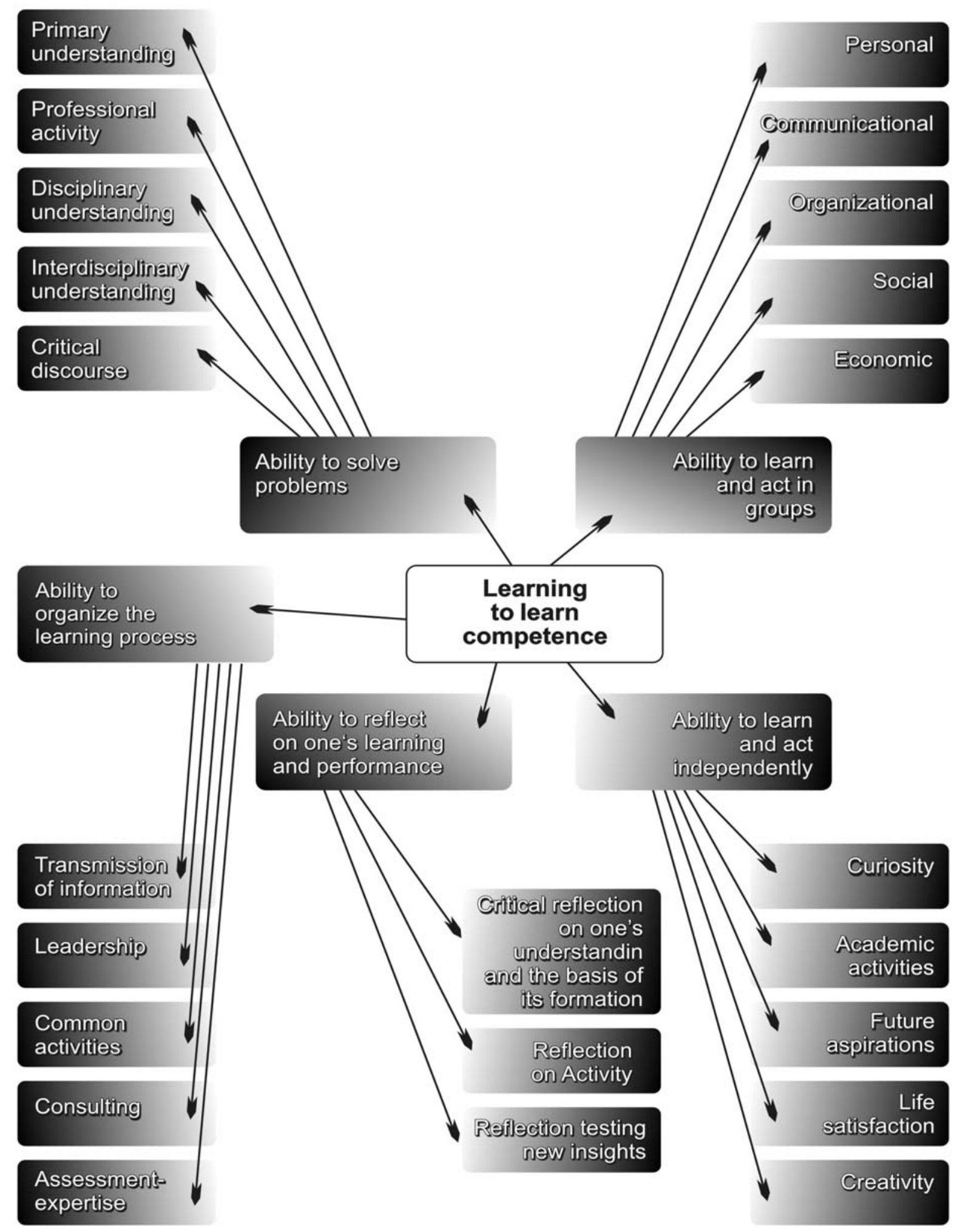

Figure 2 The model of learning to learn competence 
In summary it can be stated that the analysis of adult learning to learn competence is important for the following skills: the ability to plan and organize learning activities, the ability to solve problems, the ability to reflect on their own learning and performance, the ability to learn and to act independently, and the ability to learn from each other.

The construction of the ability to solve problems consists of the learners' understanding of the fundamentals and their professional practice, as well as an interdisciplinary understanding and critical discourse.

The analysis of other abilities used in learning to learn competence, distinguishing different dimensions, reveals a complex mixture of abilities.

The ability to plan and organize the learning process includes in this activity the transmission of communication, leadership, joint activities, counselling and assessment; - the aspect of expertise is significant. It is important to note that in the ability to reflect on one's learning and activity, the main aspect is the critical understanding and its basis, reflection: reflection on activities, reflections testing new insights.

When considering the ability to learn and function independently, one notes especially the desire for knowledge, academic performance, future aspirations, satisfaction with life and opportunities for creativity. Distinctive features of the ability to learn together with other includes personal, social, organizational, social and economic aspects.

\section{The results of the pilot research}

The survey was organized in Lithuania. The questionnaire for the respondents was given in the paper form as well as in the electronic form. The total number of respondents in the pilot survey was one hundred forty adults. The main scientific point for this pilot research was to discuss the main reasons for gaining learning to learn competence. The pilot research helped to check the instrument - questionnaire, in the future to make changes for the national quantitative research.

In the research survey the largest group of participants, 34\%, were those from 40 to 49 years of age; $28 \%$ were $30-39$ years old; $24 \%$ were $18-29$ years old; $8 \%$ were $50-59$ years old, $4 \% 70$ years and older; and $2 \% 60-69$ years old. $82 \%$ of the participants were women and $18 \%$ men so that the larger number of participants were women. According to marital status, 54\% were married and $46 \%$ were not.

$78 \%$ of the respondents in the survey had jobs. $10 \%$ ran their own businesses, while $8 \%$ were looking for work and $4 \%$ were seniors. The largest group of participants in the survey had jobs. $86 \%$ lived in towns, while $14 \%$ lived in rural areas, thus making urban people the largest group in the survey.

From the research survey it became clear that a learning to learn competence encouraged the desire to improve, as $29 \%$ of the respondents stated. $21 \%$ of the 
participants referred to the goal of self-realization. Career possibilities as a reason to learn were mentioned by $17 \%$ of participants in the survey, while $16 \%$ stated that their work required this learning. $7 \%$ of the participants indicated that they hoped this would help them find jobs. $2 \%$ of respondents mentioned the encouragement of family members to keep on learning. Other reasons were given by $1 \%$ of the participants in the survey.

Therefore the desire to improve is the main reason for those learning to learn competence. Participants in the survey also emphasized their need to realize themselves and career possibilities as helping them in this learning process.

\section{Conclusions}

- The analysis of the scholarly literature reveals the following key abilities in the formation of learning to learn competence: to organize the learning process, to learn and act independently, to learn and act in a group, to solve problems, and to reflect on learning activities.

- The model of learning to learn competence is presented. Five scenarios help to see how learning is transformed into action, as well as being important in explaining the concept of learning to learn competence.

- From the research survey it became clear that a learning to learn competence encouraged the desire to improve, self-realization, career possibilities, work requirements for learning. Therefore the desire to improve is the main reason for learning to learn. Participants in the survey also emphasized their need to realize themselves and career possibilities as helping them in this learning process.

\section{References}

1. Bendrieji visa gyvenima trunkančio mokymosi gebëjimai. Europos orientaciniai metmenys. (2007). Retrieved March 28, 2014, from http://ec.europa.eu/dgs/education culture/publ/pdf/ll-learning/keycomp_lt.pdf

2. Black, P., McCormick, R., James, M., Pedder, D. (2006). Learning How to Learn and Assessment for Learning: Theoretical Inquiry. Volume 21, Issue 2.

3. Buckingham, Shum, S. and Deakin Crick, R. (2012). Learning Dispositions and Transferable Competencies: Pedagogy, Modelling and Learning Analytics. Retrieved March 28, 2014, from http://oro.open.ac.uk/32823/1/SBS-RDC-LAK12-ORO.pdf

4. Education and Training 2020 (ET 2020). Retrieved March 28, 2014, from $\mathrm{http}: / /$ europa.eu/legislation_summaries/education_training_youth/general_framework/ef 0016_en.htm

5. Hautamaki, J., Arinen, P., Eronen, S. (2002). Assessing Learning to Learn: a Framework. Helsinki: Centre for EducationalAssessment.

6. Illeris, K. (2003). Three Dimensions of Learning: Contemporary learning theory in the tension field between the cognitive, the emotional and the social. Malabar, Florida: Krieger. $\quad$ Retrieved $\quad$ March 28, 2014, from http://www.irrodl.org/index.php/irrodl/article/view/305/480 
7. Key Competences for Lifelong Learning. European Reference Framework (2007). Luxembourg: Office for Official Publications of the European Communities. Retrieved March 15, 2014, http://ec.europa.eu/dgs/education_culture/publ/pdf/ll-learning/ keycomp_en.pdf

8. Sadzaglishvili, S.,Tsereteli, M., Berdzenishvili, T. (2008). Assessment of Learning-ToLearn Processes In Students. Problems of Education in the 21st Century. Vol. 7, p. 126132. Retrieved March 28, 2014, from Vytautas Magnus University Library http://web.ebscohost.com.ezproxy.vdu.lt

http://web.ebscohost.com.ezproxy.vdu.lt/ehost/detail?vid=6\&sid=07f6e0c2-e097-4f5197ad-82d97c48a942\%40sessionmgr4003\&hid=119\&bdata=JnNpdGU9ZWhvc3 QtbG12ZQ\%3d\%3d\#db=ehh\&AN=34183115

9. Savin-Baden, M. (2000). Problem-based learning in higher education: untold stories. Buckingham : Open University Press.

10. Scardamalia, M., Bereiter, C. (1996). Engagingstudentsin a Knowledge Society. Educational Leadership. Nov.96, Vol. 54 Issue 3.

11. Teresevičienè, M., Oldroyd, D., Gedvilienė, G. (2004). Suaugusiuju mokymasis: andragogikos didaktikos pagrindai. Kaunas:VDU 